\title{
Meggendorfer Online - Animating Movable Books
}

\author{
Marius Hug \\ Berlin State Library \\ Unter den Linden 8, 10117 Berlin \\ Germany \\ Marius.Hug@sbb.spk-berlin.de
}

\begin{abstract}
There is a long tradition of referring to books as two-dimensional objects usually made of paper. Our project deals with paper-objects, too. But digitising and modelling $19^{\text {th }}$ century movable books by the German illustrator Lothar Meggendorfer, the project BeWeB-3D aims at computer-made models of animated 19th century paper-engineered objects, which enable interaction. The human actor has to be put in a position to trigger the movement of the model. The project is located at Staatsbibliothek zu Berlin and funded by Germany's Federal Ministry of Education and Research (BMBF).
\end{abstract}

Cultural heritage. $19^{\text {th }}$ century. Movable books. Lothar Meggendorfer. Interaction. Digitisation. Modelling. 3Ds Max. Unity. Augmented Reality. Annotation.

\section{INTRODUCTION}

Movable books are not, as one could think, an invention of the $19^{\text {th }}$ century. In fact, paper-made objects containing movable parts have a long tradition dating back to the $13^{\text {th }}$ century. One of the very first samples of a movable book is Raimundus Lullus' "Ars generalis ultima" (ca. 1305), which contains a rotatable volvelle. Moreover, already Lambertus de Sancto Audomaro's "Liber Floridus" (ca. 1120) included a paper-flap which can be folded up.

The decision on using movable parts within a book for a long time was mainly based on functional considerations. And this function quite often can be described as "making the unseen visible" (Ursyn 2014): Revolvable volvelles arranged in different layers enabled calendrical calculations which otherwise would have not been possible, folding up anatomical flap-books made the inward parts of bodies accessible, and so forth.

The technological progress of the $19^{\text {th }}$ century, including the manufacturing of paper, the printing (lithography) and the colouring process (chromolithography) on the one hand, and the social developments referring to a rise of a solvent middle class and a completely altered role of books themselves on the other hand, were reasons for a real conjuncture of the production of movable (children's) books in the 1880s and 1890s.

\section{LOTHAR MEGGENDORFER}

The German illustrator and cartoonist Lothar Meggendorfer (1847-1925) became one of the main actors in the field of movable books in the late $19^{\text {th }}$ century. Beginning in 1866 Meggendorfer worked as a writer and illustrator for the Munich based humour magazine Flying Pages (see Figure 1), which started in 1844 and was like England's Punch. The Meggendorfer Pages was the title of another journal, which was first published in 1889 and did not cease to exist until 1925.

With Meggendorfer a new era started in producing children's books. His illustrations intended to break with a long tradition of designing books for children. $\mathrm{He}$ created books which worked on different levels of reception. Meggendorfer's background as a cartoonist enabled him to create a very new style of expression which reached his readers, be it children or adults, or adults reading to children. "He grasped the potential of the medium and proceeded to enlarge and deepen the child's visual pleasure [...]." (Sendak 1985)

Referring to Carola Pohlmann, head of the Department of Literature for Children and Young 
People at Berlin State Library, the most striking characteristic of Lothar Meggendorfer is his satirical perspective on the world of adults. During a time of pedagogical papers with a view to bring up courteous children, he is making fun of grown-ups in the presence of kids. (Pohlmann 2000, p. 9)

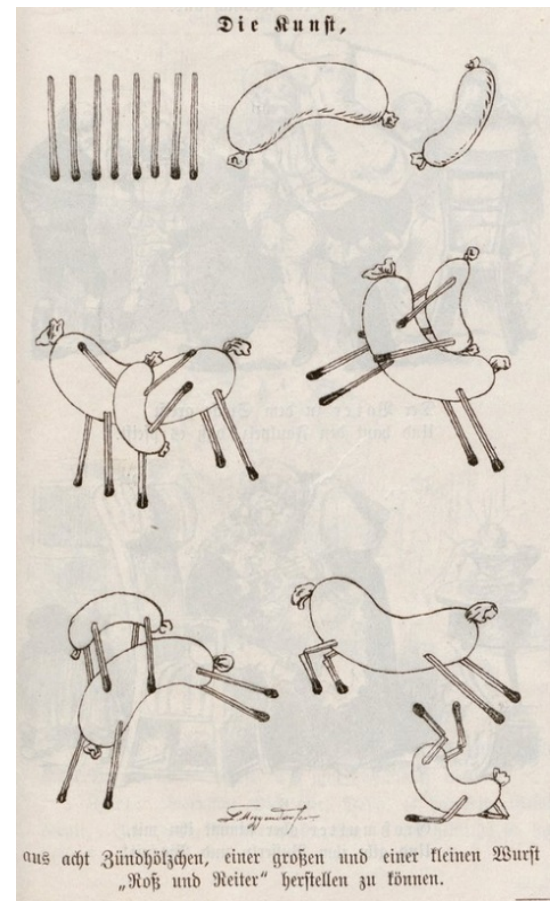

Figure 1: Meggendorfer, Lothar (1879): The art of making a horse and a rider with only eight matches, one big and one small sausage.

DOI: http://doi.org/10.11588/diglit.4941\#0043

Additionally, Meggendorfer's handmade children's books enjoyed great popularity thanks to their sophisticated fold-up, pulling and transforming mechanisms. (Bachmann et al. 2016, p. 11) He implemented complex mechanical constructions within its objects which made five or more different and often quite distant elements move simultaneously or in close succession. His movable illustrations still serve as a standard and thus Meggendorfer became and continues to be the model for so many paper engineers up to the present day. All in all it can be stated that the German era of manufacturing movable books is inextricably associated with the figure of Lothar Meggendorfer.

As far as the present era is concerned, it can be mentioned that in the U.S. the Movable Book Society regularly awards a pop-up book prize named after Meggendorfer. Due to his prominent role on the one hand and the scarcity of available copies on the other hand, today acquiring an original via an antiquarian bookseller is a fairly costly matter.

\section{DIGITISING CULTURAL HERITAGE}

Reflections on the digitisation of cultural objects following the theoretical concept of the material turn (Hicks 2010) will provoke thoughts about a wide range of objects from museums, collections, archives etc. rather than books. There is a long tradition of referring to books as two-dimensional objects usually made of paper.

Our project BeWeB-3D deals with paper-objects, too. But movable books contain an interactive level and therefore serve what one could call a third dimension. We are modelling animated 19th century paper-engineered objects. The project aims at generating a computer-made model, which enables interaction. The human actor has to be put in a position to trigger the movement of the model. The project started in February 2017, is located at Staatsbibliothek zu Berlin (Berlin State Library) and funded by Germany's Federal Ministry of Education and Research (BMBF).

In the framework of BeWeB-3D a systematic way of proceeding is essential. Our objects are books: Made of pages including text and illustrations they are as such quite ordinary elements of library catalogues. However, at the same time they are animated objects, which call for an advanced 3Dsolution concerning the digitised presentation. Categorising the different types of movable books according to the implemented level of interaction therefore became the starting point of the project: Some of them contain strips of paper to pull at, others contain volvelles which one can turn, another type includes flaps which can be folded out etc.

As regards the practical approach at the beginning of the project we established a system based on seven different classes:

(i) fold: books incl. flaps to fold out;

(ii) turn: books incl. disks to turn;

(iii) pop: books incl. real spatial volume;

(iv) pull: books incl. tabs to pull at;

(v) arrange: books incl. additional paper-made figures to play with;

(vi) mount: books incl. a function to build-up;

(vii) filter: books incl. additional material, which make some textual or pictorial information visible.

A major challenge in the digitisation of cultural heritage is the need to work across various disciplines: On the one hand, there are an innumerable amount of elaborated $\mathrm{DH}$-projects working with viewers capable of switching between different presentations: text - facsimile, XML (TEI P5) - facsimile, normalised or lemmatised speech etc. The XML files, which are the basis for these 
presentations, can be granulated quite deeply. On the other hand in the context of archaeology or architecture one can be amazed by highly sophisticated 3D-scans and appropriate presentations using the latest technology. Our objects now place themselves right in between these two very different disciplinary approaches. We are aiming at a new presentation for our cultural heritage living up to the standards of textbased digitisation projects on the one hand and to an advanced gaining and presenting of threedimensional data as well. This is challenging due to the fact that in most cases there are explicit links between the text and the visualisation. The readers are explicitly asked to turn the wheel or to pull the tab.

Last but not least BeWeB-3D aims at implementing existing tools for annotating and bookmarking certain scenes of the play. A researcher will then have the ability to create a certain stage setting, fix this setting and share it with others. This is particularly pertinent for the so called Paper Doll Books. This new type of movable books was introduced at the beginning of the $19^{\text {th }}$ century. A new toy, mostly played by girls, consisting in a text book coming with paper-made figures which sometimes could even be composed differently, simulating the dressing up of dolls. The London based S. J. Fuller became rather prominent for his doll book publications.

\section{HISTORICAL BACKGROUND}

Contrary to the function children's books had during the era of Enlightenment, when books merely served as a means for the communication of knowledge, with the start of the $19^{\text {th }}$ century they became devices of amusement and entertainment. Biedermeier was a time of collective activities: Musical rounds, rounds of talks or game parties played an important role in society. Ornamenting details and embellishment on the one, appreciation of solid craftsmanship on the other hand, can be quoted as explanations for the emergence of this new kind of children's books in addition to the character of being a toy. (Pohlmann 2017, p. 48)

The $19^{\text {th }}$ century is the time for paper theatres, too. The middle class enthusiastically enjoyed going to the theatre, a form of entertainment which had previously been restricted to aristocracy. The paper-made versions furthermore allowed for collecting pictorial broadsheets of the costumes. Unsurprisingly, some of the rather costly movable books, which were promoted as being an excellent gift to be put under the Christmas tree, came as collectibles as well, for instance the three volumes of Meggendorfer's movable animals published in 1884.
During the 19th century the industrialisation had a great impact on the making of animated toy books. This is true even though all movable books up to the present contain handmade parts. Animating these toy books in an appropriate manner will help us to explore the conditions under which movable books became a component of -19 th as well as 20th and 21st century - playrooms.

\section{INTERACTIVE ANIMATED MOVABLE BOOKS}

The technological side of the present project is realised by the Center for Digital Cultural Heritage in Museums (ZEDIKUM). A first challenge is our average scientific user who demands a lowthreshold handling which asks for at least a plug-in free solution, e.g. browser technologies based on WebGL. A second challenge is the outstanding haptic quality of the original which invites to reflect on how to live up to this standard best. Thirdly, the implementation as a dynamical 3D model possibly necessitates the use of game-engines like Unity. And last but not least the research context asks for sustainability, long-term preservation and an open international standard, e.g. CIDOC-CRM, which guarantees interoperability as well.

ZEDIKUM is specialised on 3D-digitisation of cultural heritage, for instance using the Structure from Motion technology (SfM). However, as this treatment is rather costly and time-consuming and not all our movable books contain a spatial third dimension, it needs to be reassessed which of the objects require this procedure.

Whether advanced 3D-digitisation technologies or rather ordinary flatware-scanning will be deployed, as a requirement for the desired interactive animation the crucial point is the presentation of the data. In this respect the approach of different institutions merely producing short videos of their movable children's books must be considered as rather insufficient. Interactivity then is limited to starting and stopping the video. From a technical point of view Ellen G. K. Rubin presents an only slightly advanced solution: By a simple JavaScriptbased mouse-over effect, the reader is actually capable of interactively controlling the movement using the mouse (see Figure 2).

A little bar is divided into a couple of segments each of them linked to a certain still of the animation. Moving the cursor over the bar will trigger the appropriate image and a to and fro movement will thus simulate the complete movement of the figure. This is very basic but does take the right direction. One could think of an extension to the mouse, which would take the reader closer to the original pull-movement. 
Another already existing digital solution for the before mentioned paper doll books is technically based on the Shockwave Authorware plug-in.

The Hedgehog

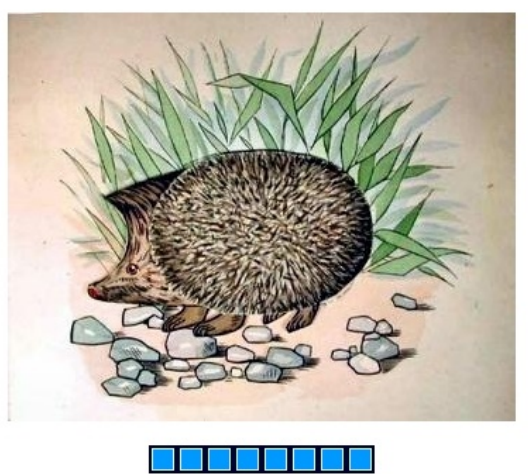

Figure 2: Ellen Rubin's way of animating a Meggendorfer illustration in Allerlei Tiere (1890). This still is seen when the cursor points to the fourth of eight segments. Moving to each end of the bar makes the hedgehog hide.

http://popuplady.com/mm02-lotharhedgehog.shtml

Our project aims at working out a technical solution working on multiple stages. We will have to serve the reader, for whom even browser-based consumption is challenging. Therefore, the access to our material has to be as intuitive as possible. To be sure there are Augmented Reality solutions; we see in these a huge potential for making our objects accessible, be this a tablet-based ARimplementation or a realisation working with headworn displays. The decisions as to which is the proper execution will have to be made on a caseby-case basis. There are movable books which make a 3D digitisation necessary and which are begging for a VR-environment to approach them, for instance the so-called peep-shows, a very popular amusement device in the first half of the $19^{\text {th }}$ century.

\section{MEGGENDORFER ON STAGE}

As mentioned before, one speciality of Lothar Meggendorfer was the hidden mechanical system of his books. The operating instructions where often part of the foreword. Usually these are rather trivial as merely the pulling of a strip of paper is required:

Now Children, dear, pray come with me And see some comic sights, You all will laugh with mirth and glee, Or should do so by rights.

When you to them your hand apply These figures dance and caper "Tis really hard" I hear you cry "To think them only paper."
The men and creatures here you find Are lively and amusing, Your fingers must be slow and kind And treat them well while using.

But more of them we must not tell, The pictures would be jealous, So turn the leaves and use them well And don't be over zealous. (Meggendorfer 1895)

But behind the stage, this action enables a fairly complex setting, controlled by ribbons and joints. So while the child just pulls a paper tab the effect is quite fascinating, as different actors on stage begin to move. "He used tiny metal rivets, actually tight curls of thin copper wire, to attach the levers, so that a single pull-tab could activate all of them, often with several delayed actions as the tab was pulled further out. Some illustrations used more than a dozen rivets." (Montanaro 2005)

Normally the intriguing mechanism remains hidden between two sheets of paper. What you get to see is just the movement of the different parts of an illustration, for instance showing a tailor who is diligently ironing a coat and thereby moving his flat iron rather close to the tail of a cat which is sitting on the ironing board, too (see Figure 3).

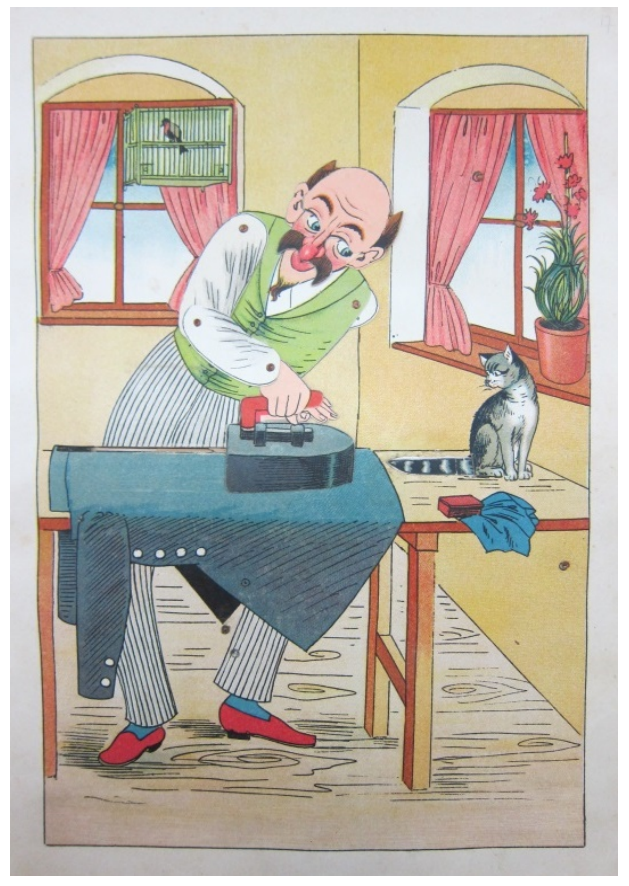

Figure 3: Meggendorfer, L. (1890). The tailor ironing a coat. The cat is pulling away her tail just in time.

However, there is a special copy in the book stock of the Berlin State Library, which gives us a glimpse of the inward parts of these books. Meggendorfer's Automatentheater is a book which deliberately has not been restored yet. The edges 
of the pages are opened and therefore the mechanism is visible (see Figure 4).

In this case, Meggendorfer made use of 12 paper levers and 16 metal rivets (some of them are not visible on the photograph) to make his illustration move. One obvious approach of digitising the tailor could be an Augmented Reality solution. Visualising the movements of the iron being held by the tailor's right hand, his left hand, his eyebrows and the cat's tail on the one side, on the other side the corresponding movements of the paper levers in the background, the reader could switch between these views and even decide for overlapping the two. This procedure would certainly stand in the tradition of making something unseen seen.

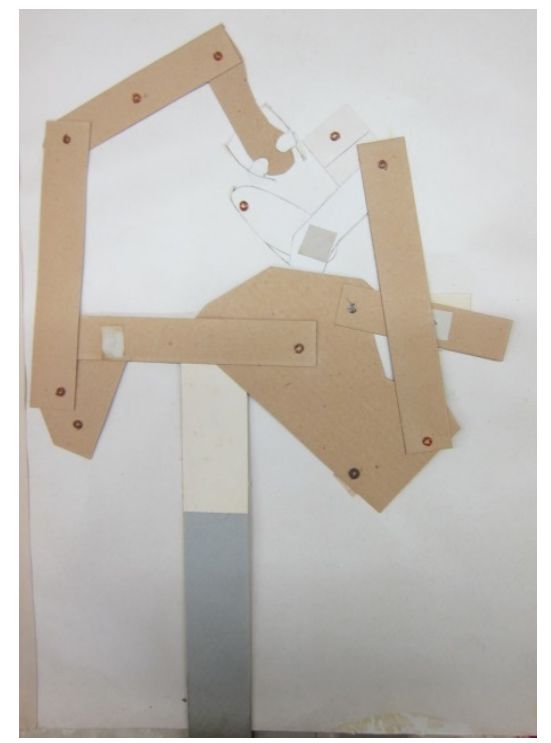

Figure 4: Meggendorfer, L. (1890). The normally hidden mechanism needed for making the tailor, the iron and the cat move.

Regarding the technical realisation, the first step is an extraction of the single parts of the mechanism. Therefore, a photograph of the picture is taken, preferably following orthographical rules. After loading this photograph into Affinity Design, the single components of the mechanism can be extracted as vector data. Due to the fact that normally there are some overlays, missing parts will have to be filled up manually in all conscience. Obviously, some expert knowledge is essential at this point. Having all components on a plane template, this broadsheet is projected as a texture on a surface and cut out digitally within 3ds Max. Afterwards all components exist as a quadmesh with textural coordinates. Again, 3ds Max is used to put together the single components.

The whole assemblage is finally loaded into Unity. There the different meshes and textures are combined to one material, which needs some calibration. Within unity all physical characteristics will have to be defined in order to attach them to the different elements. This enables an interactive control. And this control will make the interface between the digital mechanism and the augmented reality system.

\section{CONCLUSION}

Generally speaking the use of technologies originating from the context of the developments of computer games is the minimum requirement for an appropriate virtual realisation of animated historical movable books. As seen here, this observation has far reaching consequences. Although movable books are per se animated objects, they are books with a textural and pictorial layer as well. Therefore the aim of our project on a practical level is the creation of certain prototypes of virtual movable books, but on a theoretical level we want to initiate discussions on new datastandards for animated three-dimensional objects.

\section{REFERENCES}

Bachmann, Christian A., Laura Emans, and Monika Schmitz-Emans (2016) 'Pop-up-Bücher Und Movable Books. Vorbemerkungen zu den Gegenständen des vorliegenden Buches'. In Bachmann, Christian A., Laura Emans, and Monika Schmitz-Emans (eds.) Bewegungsbücher. Spielformen, Poetiken, Konstellationen. Ch. A. Bachmann Verlag, Berlin, pp. 7-18.

Meggendorfer, L. (1879) Die Kunst. Fliegende Blätter, vol. 70 , no. 1749 , p. 39 . Online available: http://digi.ub.uni-heidelberg.de/diglit/fb70/0043 (retrieved 15 March 2017).

Meggendorfer, L. (1890) Lustiges AutomatenTheater: Ein Ziehbilderbuch. Schreiber, Eßlingen.

Meggendorfer, L. (1890) The Hedgehog. In Allerlei Tiere. Braun \& Schneider, München. http://popuplady.com/mm02-lotharhedgehog.shtml. (retrieved 15 March 2017).

Meggendorfer, L. (1895) Comic Actors: A New Movable Toybook. H. Grevel \& Co., London.

Montanaro, A. (2005) A concise history of pop-up and movable books.

http://www.libraries.rutgers.edu/rul/libs/scua/monta nar/p-intro.htm. (retrieved 15 March 2017).

Pohlmann, C. (2000) "Nur Für Brave Kinder". Spielund Verwandlungsbücher Im 19. Jahrhundert. http://webdoc.sub.gwdg.de/ebook/aw/2000/sdd vor trag/Vortrag pohlmann.pdf. (retrieved 15 March 2017.) 
Pohlmann, C. (2017) Kein Kinderspiel. Spiel- und Bewegungsbilderbücher vom 17. Jahrhundert bis zur Gegenwart. In Imprimatur 2017. (Forthcoming.)

Sendak, M. (1985) The Genius of Lothar Meggendorfer: A Movable Toy Book. Random House, Inc, New York.
Ursyn, A. (2014) 'Making the Unseen Visible: The Art of Visualization'. In Perceptions of Knowledge Visualization: Explaining Concepts through Meaningful Images, pp. 277-331. IGI Global, Hershey, PA. 